\title{
Durability Investigation of plastic gears
}

\author{
Gorazd Hlebanja ${ }^{1, *}$, Matija Hriberšek ${ }^{2}$, Miha Erjavec $^{2}$, and Simon Kulovec ${ }^{2}$ \\ ${ }^{1}$ Podkrižnik d.o.o., Lesarska c. 10, 3331 Nazarje; University of Novo mesto, Na Loko 2, 8000 Novo mesto, Slovenia \\ ${ }^{2}$ Podkrižnik d.o.o., Lesarska c. 10, 3331 Nazarje, Slovenia
}

\begin{abstract}
Plastic materials can be used for various gears and gear mechanisms due to their qualities, like wear resistance when running dry, low noise, vibration damping, low inertia, low manufacturing cost, etc. However, they also expose with temperature connected problems like rapidly decreasing load, thermal expansion and accuracy of moulded gears. Therefore, it is a challenge to produce gears with adequate accuracy and durability to serve in contemporary mechatronic applications in automotive, in medical equipment and many other industries. Such materials are POM, PA6, PA66, PEEK, reinforced plastic materials, etc. and steel. Proper combination of such materials can result in long and reliable operation of such mechanisms. On the other hand, S-gears offer improved properties in comparison to involute (Egears), which essentially comprise lower contact pressure, less sliding and frictional losses, stronger root and improved oil film when lubricated. The goal is development of advanced power transmission drive components made of polymers. So, a material database, a testing system and testing procedures with varying material combinations and gear pairs according to VDI are necessary to support a designer in proper decisions. Some material properties, especially fillers are presented. Furthermore, testing facilities, gears and some results are discussed.
\end{abstract}

\section{Introduction}

One can agree on advantages of plastic gearings, which are low density resulting in reduced weight and lower moment of inertia, elasticity and impact resistance, low coefficient of friction, corrosion resistance, manufacturing cost in terms of mass production, good performance in noise, vibration and harshness. Limitations of plastic gears are in lower mechanical strength which result in lesser load-carrying capacity compared to metal gears. On the other hand, the number of available materials is growing almost at an exponential rate and various companies produce materials with similar properties as well. Proper combination of such materials can result in long and reliable operation of such mechanisms and a costeffective solution.

The paper presents some actual material combinations for gears, which can be used in complex parts. Due to immense development in materials it is necessary to assess their properties, their design value. The simplest way is to experimentally estimate durability of such material with simple, yet accurate testing rigs. Results can be then compared to the other available materials and an optimal material can be used in the design.

Since the VDI Richtlinie Blatt 4 [1] proposes standardised testing procedure for mould injected and cut gears it was necessary to design and implement a new testing rig to accommodate conforming tests.
Some tests with small plastic gears conducted to assess Wöhler curves for gears with various material combinations and long-term tests with smaller loads to run up to 10 or 20 million cycles in the controlled environment have been conducted recently [2-5]. Results comparing S- and E-gear shape indicate better performance of S-gears. S-gear geometry feature lower contact pressure, less sliding and frictional losses, stronger root and improved oil film when lubricated.

Thermal models should reflect actual gear tooth shape, which is an unaccomplished task, yet. So, frictional power along the path of contact, work of friction and deriving flash temperatures along the path of contact calculated for both gear types disclose lower thermal load of S-gears [3].

The main goal is development of advanced power transmission drive components from polymeric materials (gear pairs), which will suit the customer demands and improve gearbox lifetime. It includes optimization and development of materials, improving guidelines for gear and tool designing and expanding of material database in terms of Wohler's curves, wear coefficients, temperatures in meshing zone for typical polymeric materials, which will be the main contribution for design engineer in a real industrial environment.

\section{Thermoplastic materials for gears}

Mechanical properties of basic plastic materials can be affected by formation of voids, whereas processing

\footnotetext{
* Corresponding author: gorazd.hlebanja@podkriznik.si; gorazd.hlebanja@siol.net
} 
behaviour (shrinkage, internal stresses, moulding temperature) causes lower quality grades. It is difficult to achieve similar tolerance class and dimensional stability as in metal production, which is due to higher thermal expansion as in metals.

There is neither ISO nor European standard available for plastic gear design. However, there are some national guidelines for designing polymer gears, e.g. the Association of German Engineers (Verein Deutscher Ingenieure - VDI) that has developed the guidelines (VDI 2736 Part 1, 2, 3, 4) for plastic gears, which are widely used in industry and research $[1,6,7]$. In the United States of America, their AGMA (American Gear Manufacturers Association) published a series of standards for plastic gears. $[8,9]$. And in Japan they use JIS B 1759 (Japanese Industrial Standard) [10], which provides only guidelines for estimation of tooth bending strength of cylindrical plastic gear and is based on international standard ISO 6336-3 [11].

Thermoplasts belong to the group of plastic polymers that soften when heated and solidify again when cooled. This phenomena enable them for molding. Due to their unique chemical properties thermoplastic materials can be remolded and recycled without negatively affecting material physical properties.

With regard to gearings, thermoplastic materials should conform to some basic requirements, e.g. sufficient strength in terms of gear tooth loading, good wear and friction characteristics in combination with the material of a mating gear. Corrosion resistance is also important in some applications. Therefore, a designer has to evaluate the requirements in environmental and mechanical aspect, and compare these to the properties related to the intended materials. The most popular engineering compounds are based on the following materials: POM, PA, PBT, PE-HD, PET, and PEEK. Materials can include additives and reinforcements, which have appropriate effects on stress, friction, wear, isotrophical behaviour, etc. The properties of the plastics can be selectively influenced by the main varying aspects, e.g. the molecular weight, crystalization, copolymerisation, reinforcements, fillers, and stabilization.

\subsection{Mechanical properties}

The mechanical properties of plastics depend not only on the material but also on production and operating conditions. The following strength properties are relevant to dimensioning gear wheels: yield stress, tensile strength and breaking stress.

With increasing temperature, bonding forces among the thermoplastic molecules weaken, what results in reduced mechanical properties. So, service temperature should be considered in design as a maximal temperature increase during power transmission process.

Another important aspect is load type and duration. Under static loading a plastic part constantly deforms, it creeps. With a specified, constant deformation the stress decreases over time and the material relaxes. With dynamic loading, strength decreases as the number of stress cycles rises. High numbers of stress cycles or large elongations bring about an additional reduction in properties on account of the viscoelastic material behaviour and the heat resulting from there [7]. Viscoelastic substance has an elastic and a viscous component. The viscosity of a such substance imposes the substance a strain rate dependence on time. Purely elastic materials do not dissipate energy (heat) when a load is applied or removed [12]. Plastic deformation results in lost energy. Hysteresis is observed in the stress-strain curve, where the area in the loop equals to the energy lost during the loading cycle.

Fluctuations in humidity cause timeshifted smaller changes of moisture content in plastics. An amorphous structure binds more moisture than does a crystalline. Moisture lowers the yield stress and the modulus of elasticity. Toughness and elongation at break and also elongation at yield stress increase. In addition, the moisture content brings about an increase in volume.

Damping is characterized by the logarithmic decrement $L$ of mechanical damping, which is regarded as a loss factor and is furthermore a measure of energy loss in relation to recoverable energy. Materials with a high $L$-value damp better than those with a low value, while a value $L=0$ describes a fully elastic material [7].

\subsection{Thermal properties}

Temperature-dependent dimensional deflections have an effect on the transmission quality of the component. Additives, such as glass fibres, increase strength and consequently reduce thermal linear deformation. Thermal conductivity of plastic material is considerably lower than that of metals, which causes problems in heat removal from the meshing zone. Additives with good thermal conductivity, such as graphite and metalic additives, are able to improve the thermal conductivity but their impact in the power transsmision process is abrasive. One can improve frictional conditions on the flanks with additives - lubricants, e.g. PTFE and graphite fibers, which then result in lower temperatures in meshing zone. In order to maintain material properties at high operating temperatures, heat stabilization process is also known.

\subsection{Engineering materials}

The most common plastics used in the production of gearing include acetal and nylon. Typical representatives of these materials are POM-C - Polyacetal and PA66 Polyamide 66. However, within this group there are many variations. These materials are produced under trade names. Each of these brand names include various formulations that manipulate the product mechanical and thermal properties. They may add lubrication or improve tensile strength. Table 1 shows basic mechanical and thermal properties for POM and PA66 material.

POM has high strength, it is resistant to cleaning agents, stiff and has high toughness, material is very good for electrical insulation, its ability for machining is good, it has good slide and wear properties, but it is difficult to bond. 
PA 66 is distinguished by good sliding wear properties, material is electrically insulating, it has good wear properties, high strength, its ability to weld and bond is good, it is resistant to many oils, greases and fuels and has high toughness.

Table 1. Material properties of POM and PA66 [7]

\begin{tabular}{|c|c|c|}
\hline Property & PA66 & POM \\
\hline Density, $\rho$ & $1,13 \ldots 1,16\left[\mathrm{~g} / \mathrm{cm}^{3}\right]$ & $1,39 \ldots 1,42\left[\mathrm{~g} / \mathrm{cm}^{3}\right]$ \\
\hline $\begin{array}{l}\text { Modulus of elasticity } \\
\text { (tensile), E }\end{array}$ & 3000 [MPa] & $2600 \ldots 3200$ [MPa] \\
\hline Tensile strength, $R_{\mathrm{m}}$ & $85[\mathrm{MPa}]$ & $60[\mathrm{MPa}]$ \\
\hline $\begin{array}{l}\text { Tensile strength at } \\
\text { yield, } R_{\mathrm{e}}\end{array}$ & $84[\mathrm{MPa}]$ & $67[\mathrm{MPa}]$ \\
\hline Elongation at yield, $\varepsilon$ & $5 \ldots 7 \%$ & $9 \%$ \\
\hline Poisson's ratio, $v$ & $0,38 \ldots 0,42[-]$ & $0,42 \ldots 0,45[-]$ \\
\hline $\begin{array}{l}\text { Service temperature } \\
\text { (short term), } T_{\mathrm{m}}\end{array}$ & $140 \ldots 170\left[{ }^{\circ} \mathrm{C}\right]$ & $110 \ldots 140\left[{ }^{\circ} \mathrm{C}\right]$ \\
\hline $\begin{array}{l}\text { Service temperature } \\
\text { (long term), } T\end{array}$ & $80 \ldots 100\left[{ }^{\circ} \mathrm{C}\right]$ & $90 \ldots 100\left[{ }^{\circ} \mathrm{C}\right]$ \\
\hline $\begin{array}{l}\text { Thermal expansion } \\
\text { (CLTE), a }\end{array}$ & $11 \ldots 12 \times 10^{-5}\left[\mathrm{~K}^{-1}\right]$ & $13 \ldots .14 \times 10^{-5}\left[K^{-1}\right]$ \\
\hline Thermal conductivity, $\lambda$ & $0,23 \ldots 0,36[\mathrm{~W} / \mathrm{K} . \mathrm{m}]$ & $0,25 \ldots 0.39$ [W/K.m] \\
\hline Specific heat, $c$ & $1,5[\mathrm{~J} / \mathrm{g} \cdot \mathrm{K}]$ & $1.4[\mathrm{~J} / \mathrm{g} . \mathrm{K}]$ \\
\hline Thermal diffusivity ${ }^{*}, X$ & $0,207 \ldots 0,136\left[\mathrm{~mm}^{2} / \mathrm{s}\right]$ & $0,128 \ldots 196\left[\mathrm{~mm}^{2} / \mathrm{s}\right]$ \\
\hline
\end{tabular}

These materials can include various fillers to improve strength or frictional properties. Materials can be found in various databases [13-15], which collect data according to specific requirements, so data extraction can be time spending task.

\subsection{Additives}

\section{Fillers}

Fillers inexpensive, inert, inorganic materials that add bulk to the plastics, reducing raw material cost. However, they can improve the moldability and stability of the plastic, they increase the heat-deflection temperature and reduce the thermal expansion when heated. Common minerals are aramide fibers, glass fibers, ceramic, metals [16].

\section{Aramide fibres}

Aramide fibres are linear, organic polymers with high strength and stiffness, in which covalent bonds are oriented along the fiber axis with the tightest possible packing density. The aramid filament density is at 1,45 $\mathrm{g} / \mathrm{cm}^{3}$ and lower compared to the other fibers. They are strongly anisotropic, (properties in the fibre direction differ significantly from those across the fibres). So, the strength or the modulus od elasticity in the fibre direction is much higher than in the perpendicular direction. The compressive strength in the fibre direction is several times lower than the tensile strength [17].

\section{Glass fibres}

Textile fibre is the collective term for fine fibres spun from molten glass with approximately round crosssection. The relatively high strengths and modulus values are a consequence of the strong covalent bonds between silicon and oxygen in the three-dimensional network of the glass. Due to their amorphous structure, glass fibres are isotropic in contrast to carbon and aramid fibres. The tensile strength exceeds that of most organic and inorganic fibers and is sometimes significantly higher than that of steel $\left(1500 \mathrm{~N} / \mathrm{mm}^{2}\right)$. From the thermal aspects they do not reduce mechanical properties even for continuous loads up to $250^{\circ} \mathrm{C}$ [17].

\section{Glass spheres}

Microscopic solid glass spheres added to a plastics compound give smoothness, hardness, and excellent chemical resistance, with low oil absorption. They have the appearance of a fine white odourless powder, in diameter ranges up to $850 \mu \mathrm{m}$. The advantages can be summarized as: improved processability; low, uniform shrinkage; low warpage; close tolerances; improvement in surface finish; improved distribution of stress; reduction in deformation under load; resistant to most chemicals; improved abrasion resistance; low coefficient of thermal expansion; high thermal resistance [18].

\section{Lubricants}

Lubricants are additives that improve the processability of the resin and prevent damage to the moulding equipment by reducing friction (external lubricants), and by lowering the bulk viscosity (internal lubricants) [16].

\section{Internal lubrication}

The coefficient of friction of the dry-running gear wheel can be reduced by adding suitable fillers. Furthermore, this will also improve wear, service life and efficiency. However, care is necessary since many additives can improve the tribological properties but also worsen mechanical properties. Many fillers and reinforcing materials, which influence the mechanical and tribological properties of plastics, are presented in Table 2.

\section{External lubrication}

Lubricating greases can be based on both, synthetic and mineral oil. The synthetic lubricating greases are more aging-resistant and in comparison with thermoplasts behave in most cases neutrally as regards stress, corrosion and swelling. Their viscosity temperature behaviour is particularly advantageous. Greases based on mineral oil can cope with higher pressures and have better lubricating performance. The lubricant used must adhere firmly to the slide face, even at higher operating temperatures. Selection of the lubricant will depend on the operating conditions to which the gear wheel to be lubricated is exposed [7].

\section{Testing facilities}

Up to present two small testing rigs were used to acquire gear durability data. They were described in detail in several papers $[19,20]$. Small gears $(m=1 \mathrm{~mm}, \mathrm{z}=20, \mathrm{~b}=$ $6 \mathrm{~mm}$ ) of variing materals were exposed to a constant torque and run until failure. In this way Wöhler curves are obtained. While small gears are not demanding with regard to production cost and are modest in operating 
Table 2. Properties of fillers and reinforcing materials [7]

\begin{tabular}{|c|c|c|}
\hline Filler & Positive influence & Negative influence \\
\hline $\begin{array}{l}\text { glass, carbon or } \\
\text { aramid fibres }\end{array}$ & $\begin{array}{c}\text { increase in stiffness, tensile strength, flexural fatigue strength } \\
\text { and heat distortion resistance }\end{array}$ & reduction in impact strength \\
\hline PTFE & reduction in friction and wear & $\begin{array}{l}\text { reduction in impact strength and } \\
\text { flexural fatigue strength }\end{array}$ \\
\hline $\mathrm{PE}$ & reduction in friction & reduction in impact strength \\
\hline $\begin{array}{l}\text { graphite, boron } \\
\text { nitride }\end{array}$ & $\begin{array}{l}\text { reduction in friction and wear, increase in thermal } \\
\text { conductivity }\end{array}$ & reduction in impact strength \\
\hline silicone oil & reduction in friction and wear, increase in toughness & l \\
\hline mineral fillers & increase in heat distortion resistance & / \\
\hline
\end{tabular}

power requirements, the new VDI Richtlinie, Blatt 4 [1], prescribed some other gear sizes, depending on production means. Therefore it was decided to produce a new testing rig. Two goals are 1) to produce tests comparable to a broader professonal community and 2) to discover proper correction factors for tests with small testing rigs.

\subsection{Testbench according to VDI testing}

Special purpose testbench is developed and designed for testing the cylindrical spur or helical gear sets in accordance with [1], both »Size $01 \ll$ or »Size $02 \ll$, or customer specific for a company's special purposes. The testbench is designed for both steel-polymer or polymerpolymer gear set. Fig. 1 represents the device schematically, whereas Fig. 2 shows the layout.

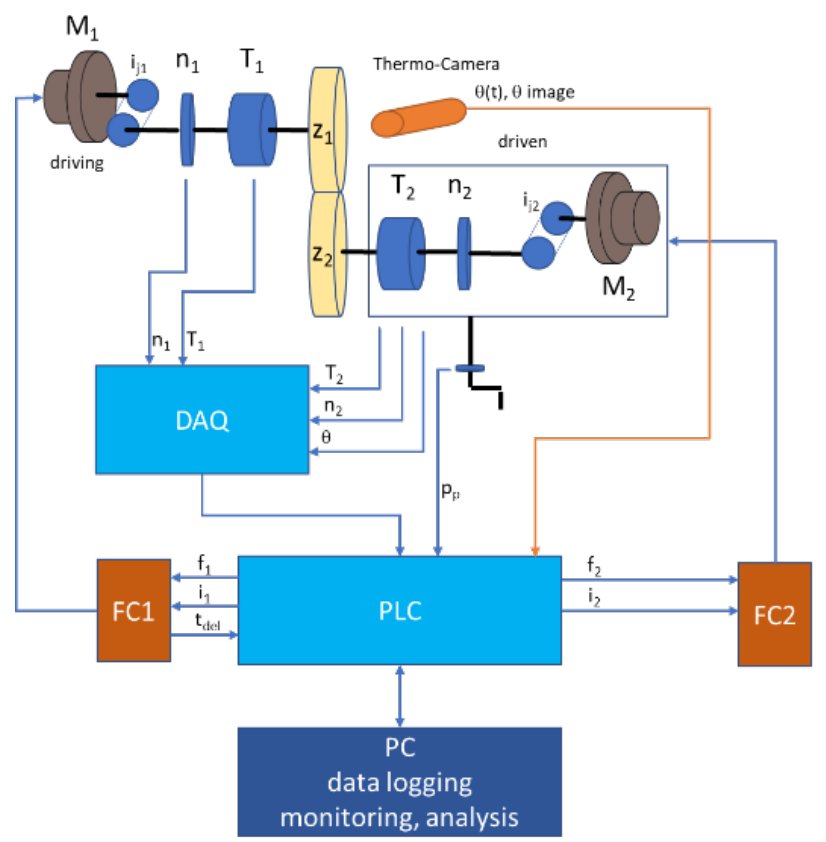

Fig. 1. Scheme of the testing bench for durability testing

The essential asset of the testbench is exact counting of load cycles from the test start until test end i.e. tooth failure $\left(t_{\mathrm{del}}\right)$.
The testbench consist of two squirrel cage asynchronous motors $\left(M_{1}, M_{2}\right)$ driven by frequency converters $\left(F C_{1}, F C_{2}\right)$ with an internal PLC controlling the testbench operating parameters (load and speed). Further, the testbench is equipped with the thermocamera providing the relevant information of the temperature distribution of the gear set being tested. The camera may be installed in a perpendicular direction to the gear meshing plane (shaft axis), with an observation point directly on the tooth flanks or it may be positioned to observe the gear face with a small inclination angle with regard to the shaft axes orientation. The camera acquires spot temperature to the $P L C$, while the thermalimages are sent to the $P C$ periodically. The Optris $\mathrm{Xi}$ 400 device is used with automatic zooming, hot spot finder, IR sensor resolution of $382 \times 288$ points and frequency of $80 \mathrm{~Hz}$.

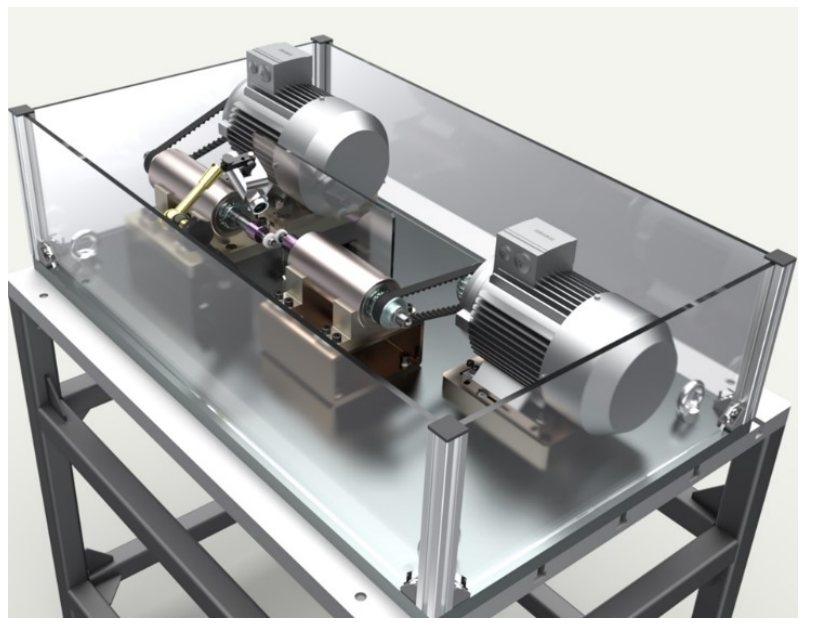

Fig. 2. Layout of the testing bench.

The operating principle of the testbench is based on the operating characteristics of the squirrel cage asynchronous motors, driven by the frequency converter. The target speed of the primary gear is set, from which the excitation frequencies of both motors, considering gear ratios, are calculated (not necessary having the same value) by the PLC itself. After gear speed is reached the load is applied by altering the excitation frequency of the driven motor, hence the slip and consequently the load on both motor changes. The actual 
load transmitted through the gear set is evaluated with the pre-calibrated lookup tables. Once the failure of the gear set is detected, the testbench stops automatically. Since the counting of the load cycle is, beside the load level, an essential information, it is provided by the testbench $P L C$.

All relevant data i.e. the evaluated load, speed, temperature and the load cycle are stored in an internal $P L C$ in a digital form throughout the test-run.

\subsection{Gears}

Manufacturing means of plastic gears can be injection moulding or cutting. Cut gears are of industrial interest for smaller lots and when a more precise tooth flank shape is prescribed or if differing gear tooth flanks are observed. Actually, comparing cut and moulded gears of the same module and number of teeth by measurements of the quality Q according to DIN 3961 or DIN 3962 discloses at least for two grades higher Q of cut gears. Measuring gears on Wenzel GearTec coordinate measurement machine in our case showed $\mathrm{Q}=9$ and $\mathrm{Q}=11$ for cut and moulded gears, respectively [2].

Regarding our past experience with moulded and cut gears it was decided that basic disks of plastic materials of interest are injection moulded, using an axial sprue enabling higher material flow, so as to gain quality uniform physical characteristics and evenly distributed fillers (when applicable). Disks are then cut by a HSS cutting hobb on the CNC Koepfer machine tool as to enable effective manufacturing.

Various plastic materials (mostly POM and PA66 based) are used with or without fillers, reinforcements and lubricants.

Beside other sizes, gears with $m=1.0 \mathrm{~mm}, z_{1}=z_{2}=20$, $b=6.0 \mathrm{~mm}$ are in use. The initial pressure angle of the Sgears $\alpha_{\mathrm{w} 0}=18^{\circ}$ and $\mathrm{a}_{\mathrm{p}}=1.5$, whereas standard pressure angle $\alpha_{w}=20^{\circ}$ is used.

Gears planned for the new testing rig are:

a) size 1: $m_{\mathrm{n}}=1 \mathrm{~mm}, z_{1}=17, z_{2}=39, b_{1}=8 \mathrm{~mm}$, $b_{2}=6 \mathrm{~mm}$.

b) size 2: $m_{\mathrm{n}}=2 \mathrm{~mm}, z_{1}=30, z_{2}=30, b_{1}=13 \mathrm{~mm}$, $b_{2}=12 \mathrm{~mm}$.

c) custom gear combinations.

Establishing stable and uniform testing conditions is of the utmost importance in this contest. These include manufacturing conditions, starting with injection moulding. So, inappropriate conditions may result (among other) in voids (Fig. 3). Results of testing gears of such material are incorrect. E.g. the driving gear is made of steel C45R, the driven gear is made of Lubricomp KA000M, which is essentially POM containing aramid and proprietary lubricant. The testing torque was $M=1,5 \mathrm{Nm}$, the temperature at failure was between 48 and $49^{\circ} \mathrm{C}$ and the time of failure between $22^{\prime}$ and $53^{\prime}$. This amounts to $2,944 \times 10^{4}$ up to $7,118 \times 10^{4}$ cycles. Teeth broke deep in the root (Fig. 4) due to the bending fatigue. The process starts in areas with more or bigger void area inside the root. The rest of teeth are undamaged, but they exhibit some initial wear on the flanks.

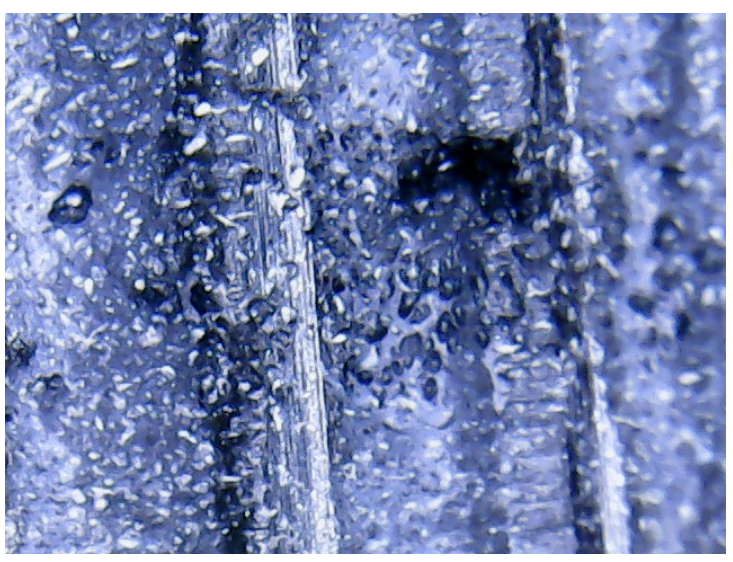

Fig. 3. Voids observed in an E-gear $m=1 \mathrm{~mm}, \mathrm{z}=20$

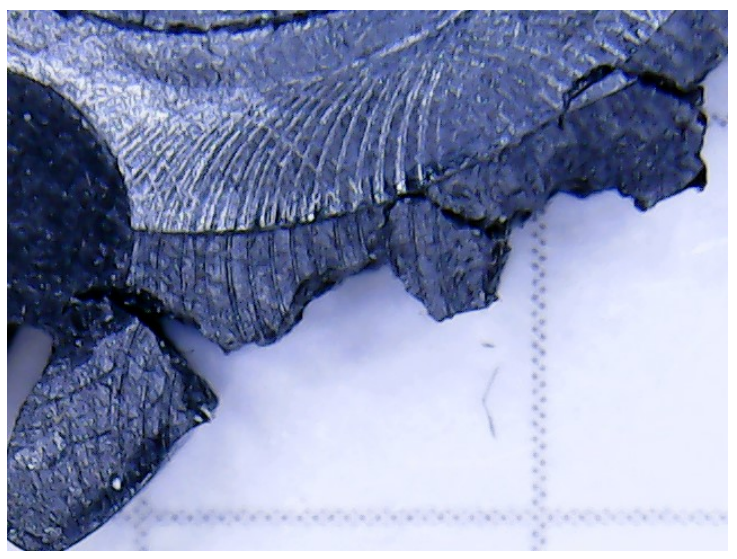

Fig. 4. Root bending breakage

\section{Crucial S-gear properties}

Several papers have been written clarifying the idea of S-gears in detail [19-22]. Some essential properties are summarized in this chapter. S gears feature a convexconcave contact in the meshing start and end areas, which can be achieved by a progressively curved path of contact, which is half symmetric. So, the generating rack profile (cutting tool) is defined in a following way:

$$
y_{P}=a_{p}\left(1-\left(1-x_{P}\right)^{n}\right)
$$

This parabolic type function defines the upper part of the rack profile whereas its counterpart is derived as a half-symmetric function. The unit of measurement is the module $m$ and $a_{p}$ as a height factor and $n$ as curvature exponent define a rack flank shape. $y_{p}$ and $x_{p}$ are the rack flank coordinates with the origin in the kinematic pole C. Such a rack profile defines a unique path of contact and out of there gears with any number of teeth can be derived with a bijective transformation.

The most important features of S-gears with regard to plastic materials are summarized below:

Tooth flank shape can be optimized by a height factor $a_{p}$ and exponent $n$, which enable gear tooth design according to prescribed properties. A stronger tooth root, a longer convex-concave area, a curvature of the path of contact, a lower starting pressure angle in $\mathrm{C}$, etc. can be defined. 


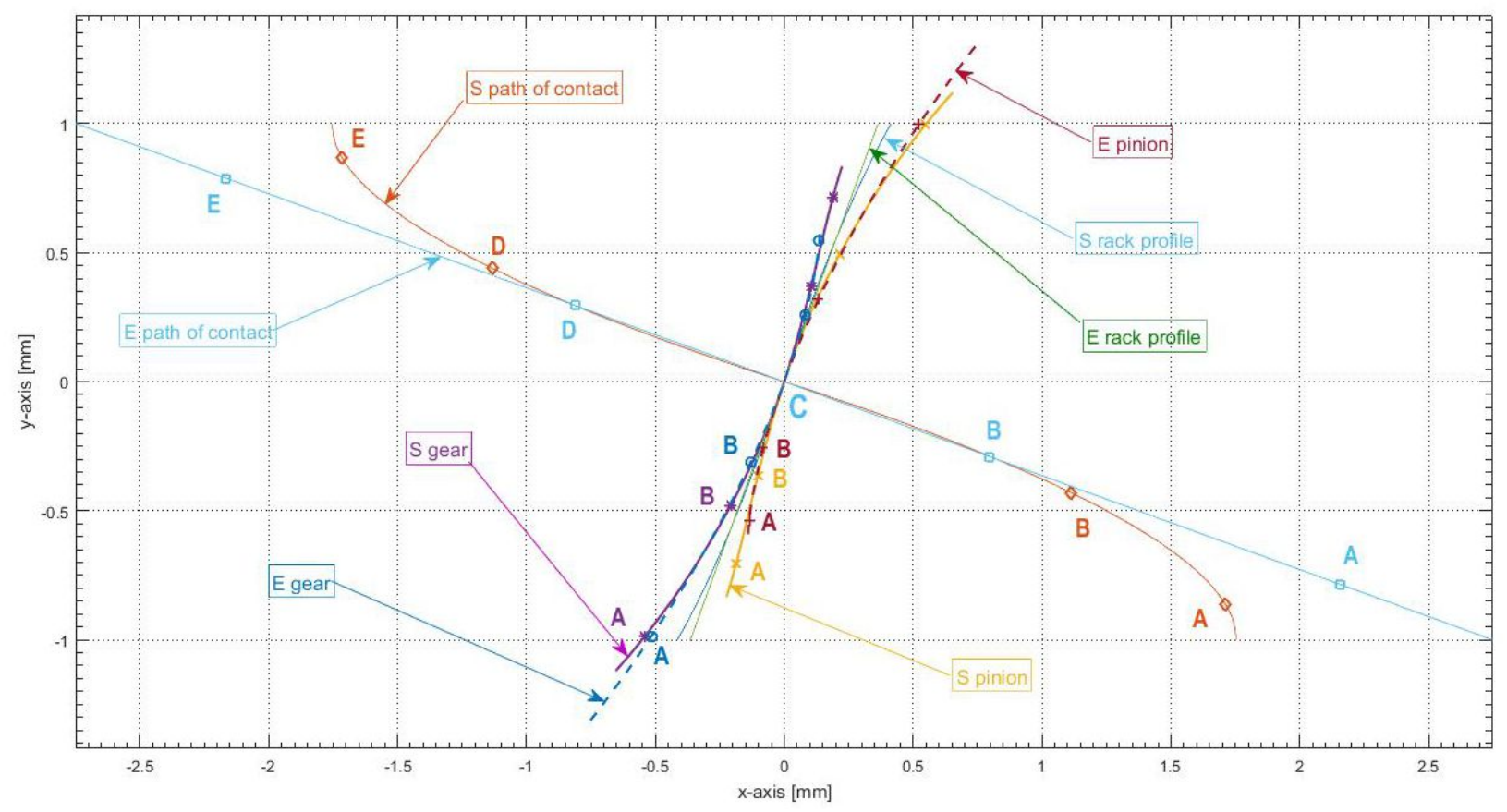

Fig. 5. Comparison of tooth flanks for $\mathrm{S}$ - and E-gears, $\mathrm{m}=1 \mathrm{~mm}, \mathrm{z}_{1}=\mathrm{Z}_{2}=20, \alpha_{\mathrm{w} 0}=18^{\circ}$ for S-gears, $\alpha_{\mathrm{w}}=20^{\circ}$ for E-gears

- Spur S-gears can successfully operate with a very low number of teeth, six or even four teeth.

- S-gears feature convex-concave contact in a vicinity of meshing start and end. This implies higher reduced radii of curvature and results in lower contact pressure.

- S-gears feature relatively longer dedendum part of a tooth flank (comparing to the involute gears). So, in general, one could observe less sliding of a contacting pinion dedendum and gear addendum which results in less frictional work and lower temperature [21].

The situation is illustrated in Fig. 5 for gear geometries used in testing. However, if E- and Sdedendum flanks are compared, they distinct clearly, so the S-dedendum is considerably longer than Ededendum. At the same time addendums are comparative longer. Rolling and sliding appear during meshing in both cases, that is for S- and E-gears. Amount of sliding is governed by the contacting dedendum and addendum flank length difference, by the so-called contact point density. The contact proceeds slowly in the dedendum part and more rapidly in the addendum part. And the obvious difference between E- and S-gears means more sliding and thermal impact in the case of E-gears, which is illustrated in Fig.6 [3].

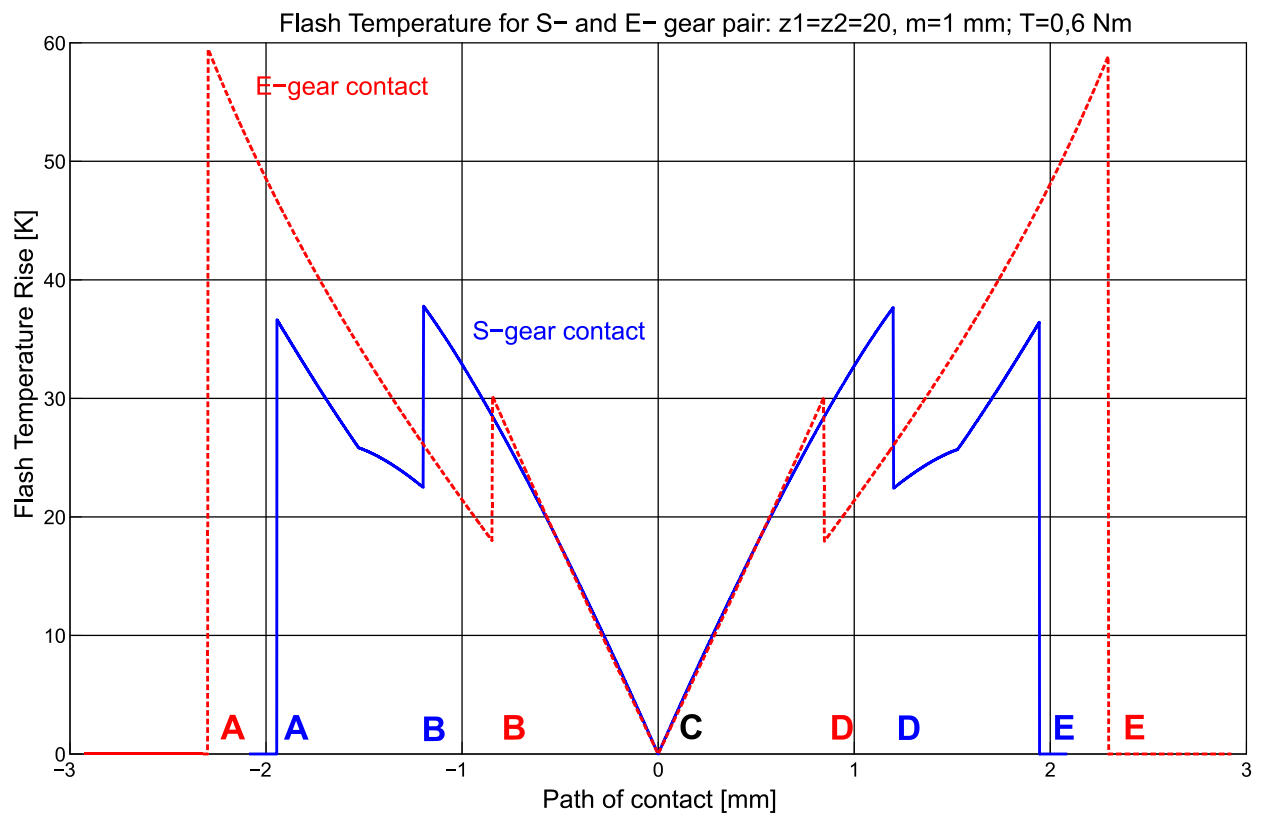

Fig. 6. Flash temperature diagram comparing tooth flanks for $\mathrm{S}$ - and E-gears $\mathrm{T}=0,6 \mathrm{Nm}, \mathrm{m}=1 \mathrm{~mm}, \mathrm{z}_{1}=\mathrm{Z}_{2}=20, \alpha_{\mathrm{w} 0}=18^{\circ}$ for S-gears, $\alpha_{\mathrm{w}}=20^{\circ}$ for E-gears 
The flash temperature calculation in the diagram is based on the already defined E- and S- gear geometries and input data complying to the experimental work, that is $\mathrm{T}=0,6 \mathrm{Nm}$ and driving wheel rotational frequency $\mathrm{n}=1439 \mathrm{~min}^{-1}$. Materials for the driving and driven gear were POM and PA66, respectively. It is obvious that Egears collect more frictional heat. The average frictional power for above data was $2,4935 \mathrm{~W}$ for S-gears and 3,0644 W for E-gears [3].

\section{Experimental results}

Previous research showed a clear distinction between Sand E-gear geometry in favour of former, which can be attributed to already mentioned attributes of S-gears [25]. Two types of experiments were conducted:

a) durability tests where gears made of POM (driving) and PA66 (driven) run up to failure and tests where both gears were made of POM;

b) long term tests up to about 20 million cycles.

The rotational frequency and torque were set at experiment start. Tests were run at room climate circumstances. Tests confirmed theoretical assumptions. However, long term tests are time consuming and were conducted in circumstances where ambient temperature varied to high extent, so additional tests are necessary.

Current experiments with renewed testing equipment have been conducted in order to:

- fine-tune equipment,

- to calibrate sensorics,

- to prepare testing protocols,

- to initially check gear materials and possible invisible faults (e.g. voids, Fig. 3, 4), etc.

These actions are necessary for the future extensive testing, which will be prevailingly focused on the VDI testing concept [1] with prevailingly size 01 gears and required temperature control. Gears used in the current tests are involute with $\mathrm{z}=20, \mathrm{~m}=1 \mathrm{~mm}$ and $\mathrm{b}=6 \mathrm{~mm}$. Tests are summarized in Fig. 7. The rotational frequency was 1400 RPM and loads $\mathrm{T}=1,1,1,3$, and 1,5 Nm.

The tested material pairs (driving / driven):

1. Lubricomp KA000M (POM with a proprietary lubricant and aramid fibres) and Lubricomp RFP36 (PA66 with glass fibres and PTFE lubricant)

2. Lubricomp RFP36 and Lubricomp KA000M

3. Lubricomp KA000M and Zytel 103 HSL NC010 (PA66, lubricated and heat stabilized)

4. Lubricomp KA000M and Luvocom 1/GF/30/TF/15/ SI/2-2 (PA66 with glass fibres, PTFE lubricant and heat stabilized)

5. C45R steel and Lubricomp RFP36

For comparison, Tecaform (POM) Tecamid (PA66) results [4] are presented, with a far better durability. Gears are with the same geometry, experiments conducted on the basically the same machine. Both materials are without inclusions and in the form of extruded bars and gears cut on Koepfer machine with a mill cutter.

Despite the presented tests are not conclusive, the best performance can be observed with a combination Lubricomp KA000M (POM) and Zytel 103 HSL NC010
(PA66), both with internal lubricant and POM also with aramid fibres. Poor performance (trend towards fatigue strength) can be observed with Lubricomp KA000M (POM) and Lubricomp RFP36, both materials with internal lubricant and PA66 (the latter) also with glass fibres. And the worst was a combination Lubricomp KA000M (POM) and Luvocom 1/GF/30/TF/15/SI/2-2 (PA66 with glass fibres, PTFE lubricant and heat stabilised). Far better performance would be expected. The reason for inadequate results is appearance of voids, deriving from gear raw parts, which are injection moulded. This problem has been observed and a new insert for the mould produced.

Table 3. Breakage temperatures for material combinations Materials used for tested gears

\begin{tabular}{|r|r|r|r|}
\hline & \multicolumn{4}{|c|}{ Breakage temperature (avg) [ $\left.{ }^{\circ} \mathbf{C}\right]$} \\
\hline Torque $[\mathrm{Nm}]$ & 1,5 & 1,3 & 1,1 \\
\hline 1 & 79,4 & 71,2 & 65,1 \\
\hline 2 & 67,2 & 62,5 & 58,4 \\
\hline 3 & 62,5 & 64,9 & 62,1 \\
\hline 4 & 85,3 & 70 & 66,9 \\
\hline
\end{tabular}

Breakage temperatures for induced torques of 1,5, 1,3 , and $1,1 \mathrm{Nm}$ and $1400 \mathrm{RPM}$ for material combinations defined in a paragraph above are depicted in Table 3. For a combination steel PA66 a breakage temperature was about $50^{\circ} \mathrm{C}$ and for Tecaform and Tecamid about $100^{\circ} \mathrm{C}$, which is also a continuous temperature limit in this case. Also, the means of failure was prevailingly thermal. For the metal plastic combination one can conclude that a mechanism of heat conductivity and heat dissipation differs from that of plastic solely. Regarding breakage temperatures in Table 4, they appear to be far below temperature limits of these materials, internal lubrication has a positive influence in this context. In fact, the breakage mechanism was fatigue bending. Nevertheless, results (Fig. 7) should be better, the most apparent reason are voids in the moulded raw parts.

\section{Conclusion}

For any given material pair, the allowable load of mating gears depends on numerous factors, like: total lifetime cycle; intermittent or continuous duty; environmental conditions (temperature, humidity, chemicals, etc.); change in diameter and centre distance with temperature and humidity; tangential velocity; number and size of teeth; tooth form; accuracy of tooth form; eventual helix angle; material combination; gear surface finish and hardness; absence or type of lubrication (implying frictional heat). So, the knowledge of mechanical, physical and thermal properties of materials becomes of crucial importance. And many necessary data are unavailable.

The paper emerged as a part of research project in which the main goal is development of advanced power transmission drive components made of polymers 


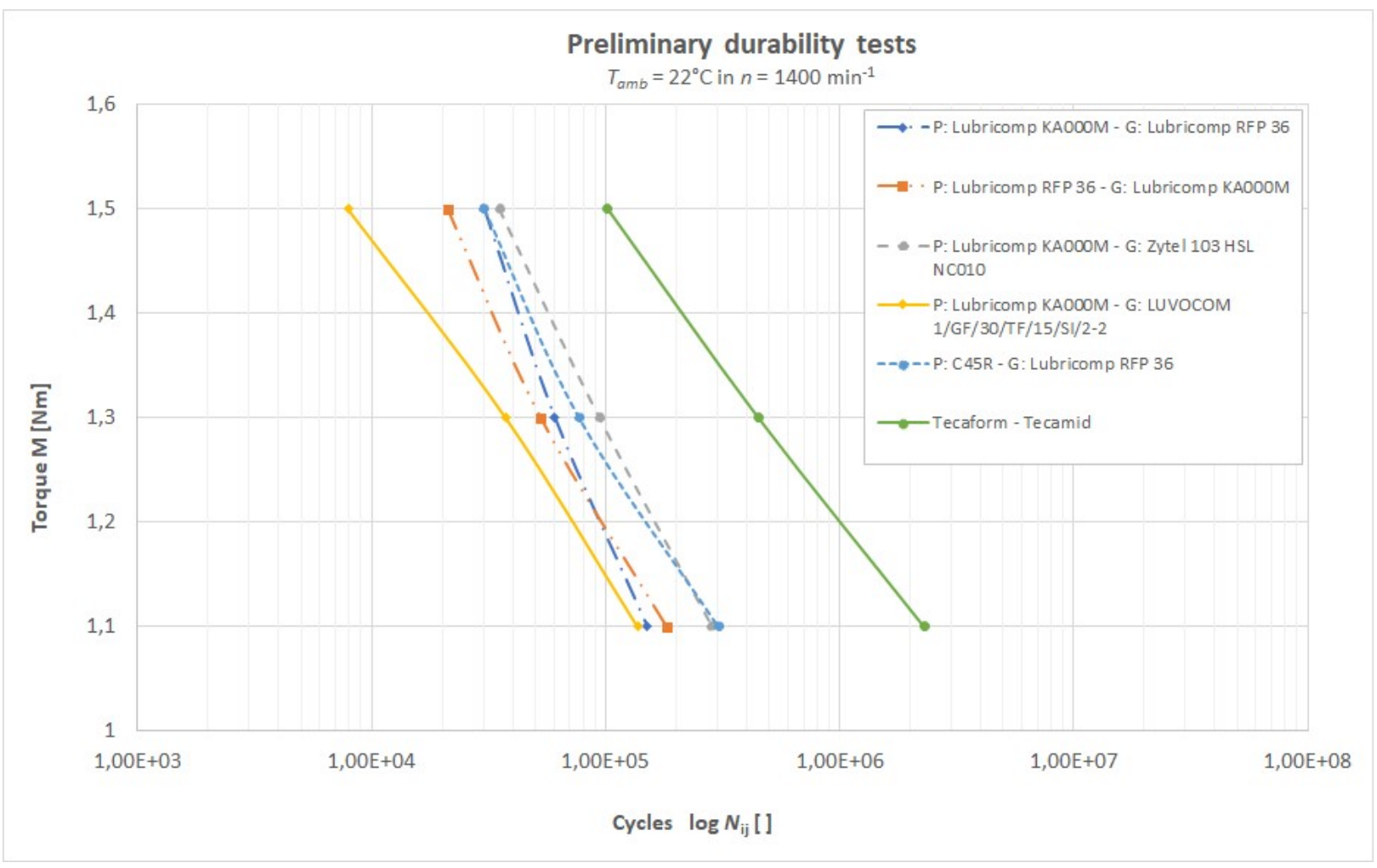

Fig. 7. Preliminary durability tests with E-gears, $m=1 \mathrm{~mm}, \mathrm{z}_{1}=\mathrm{z}_{2}=20, \alpha_{\mathrm{w}}=20^{\circ}$ (driving gear material - legend left, driven material - legend right)

materials, especially various gear arrangements, which will suit the customer demands and improve gearbox lifetime. This includes optimization and development of materials, improving guidelines for gear and tool designing and expanding of material database in terms of Wohler's curves, wear coefficients, temperatures in meshing zone for typical polymeric materials, which will be the main contribution for design engineer in a real industrial environment.

The testing system and procedures, gears and materials described in the paper are focused towards our goals, above all, building a material data base of relevant materials, which would enable optimal design decisions.

Besides, the goal is to compare different gear tooth flank geometries (E- and S-gears) since initial results are in favour of S-gears. So small gears, size 01 gears and some special arrangements will be manufactured and tested in the same way as E-gears

\section{Acknowledgement}

The investment is co-financed by the Republic of Slovenia and the European Union under the European Regional Development Fund, no. SME 2/17-3/2017 and C3330-18952014

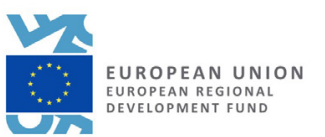

\section{References}

1. VDI 2736: Part 4. Thermoplastic gear Wheels: Determination of Strength Parameters on Gears. VDI Richtlinien (2016).

2. Hlebanja, G., Kulovec, S., Hlebanja, J., Duhovnik, J., Experimental determination of S-gear characteristics made of plastics. Polytrib 2016, 2nd International Conference on Polymer Tribology, 15th-16th September 2016, Ljubljana, Slovenia.

3. Hlebanja, G., Kulovec, S., Zorko, D., Hlebanja, J., Duhovnik, J. Influence of the tooth flank shape on thermal load of the gear. Europe invites the world, International Conference on Gears, Technische Universität München, Garching, Sept. 13th to 15th, 2017, (VDI-Berichte, ISSN 0083-5560, 2294.2). Düsseldorf: VDI. 2017, p. 15831592 ,

4. Zorko, D., Kulovec, S., Tavčar, J., Duhovnik, J. Different teeth profile shapes of polymer gears and comparison of their performance. Proceedings of MPT2017-Kyoto, The JSME International Conference on Motion and Power Transmissions February 28 -March 3, 2017, Kyoto, Japan

5. Trobenar, B., Kulovec, S., Glodež, S. The influence of gear flank shape on the service life of polymer gears, Polytrib 2016, 2nd International Conference on Polymer Tribology, 15th-16th September 2016, Ljubljana, Slovenia.

6. VDI 2736: Part 1. Thermoplastic Gear Wheels: Materials, Material Selection, Production Methods, Production Tolerances, Form Design. VDI - Richtlinien, (2016).

7. VDI 2736: Part 2. Thermoplastic Gear Wheels: Calculation of the Load-Carrying Capacity. VDI Richtlinien, (2014). 
8. ANSI/AGMA 1106-A97: Tooth Proportions for Plastic Gears, (1997).

9. AGMA 920-A01: Materials for Plastic Gears, (2001).

10. JIS B 1759: Estimation of tooth bending strength of cylindrical plastic gears. Japanese National Standard, (2013).

11. ISO 6336: Calculation of load capacity of spur and helical gears, Parts 1-6, International standard, (2006).

12. M.A. Meyers, K.K. Chawla, Mechanical Behavior of Materials, Cambridge University Press, (2008), ISBN 9780521866750.

13. MatWeb-Material Property Data: http://www.matweb. com/index.aspx, acc. 2019/04/29.

14. Omnexus - The material selection platform: https:// omnexus.specialchem.com/selectors, acc. 2019/04/29.

15. CAMPUS $^{\circledR}$ - a material information system for the plastics industry: https://www.campusplastics.com/campus/, acc. $2019 / 04 / 29$

16. Polymer Properties database, https://polymerdatabase. com/Additives/Polymer\%20Additives.html, acc. $2019 / 04 / 22$

17. G.W. Ehrenstein, Polymer Werkstoffe, Struktur-Eigenshaften-Anwendung, Hanser Verlag, München, 2011. ISBN: 978-3-446-42283-4.

18. Murphy, J. Additives for Plastics Handbook, 2nd Ed., Elsevier, B.V. 2001, ISBN 978-1-85617-370-4.

19. Hlebanja, G., Hlebanja, J. Contact circumstances of the highly loaded, low speed gears. Proceedings KOD 2012, 24-26 May, 2012, Balatonfüred, Hungary. p. 21-26

20. Hlebanja, G. Characteristics of non-involute gears. Proceedings, University of East Sarajevo, Faculty of Mechanical Engineering. 2012, p. 9-20.

21. Hlebanja, G. Specially shaped spur gears - a step towards use in miniature mechatronic applications. Proceedings, The 7th International Scientific Conference Research and Development of Mechanical Elements and Systems IRMES 2011, Zlatibor, 27-28. April 2011, Serbia. P. 475480.

22. Hlebanja, G., Hlebanja, J. Spur gears with a curved path of contact for small gearing dimensions. International Conference on Gears, Garching near Munich, Germany, 4-6. 10. 2010 (VDI-Berichte, ISSN 0083-5560, 2108). VDI-Verlag. 2010, p. 1281-1294. 